\title{
Pemanfaatan Blog Sebagai Media Berbagi Informasi dan Komunikasi : Sebuah Kajian Tulisan Blog Pada Mahasiswa Universitas Terbuka
}

\author{
Yasir Riady \\ Universitas Terbuka, Indonesia \\ yasir@ecampus.ut.ac.id
}

\begin{abstract}
Abstrak
Blog atau web blog merupakan salah satu aplikasi web yang sangat popular saat ini berisi tulisan yang bisa di akses secara online. Tulisan yang tersaji di Blog merupakan salah satu bagian dari media digital yang cukup digemari dalam membahas serta berbagi informasi secara cepat dan akurat. Kajian ini memaparkan penggunaan tulisan blog yang digunakan dari sisi informasi, perbandingan, materi konten dan gagasan tulisan yang di unggah secara tertulis. Metode penelitian pada tulisan ini adalah metode kualitatif, dengan analisis atau kajian teks yang terdapat pada tulisan blog pada mahasiswa Universita Terbuka. Kajian ini mencoba menelaah jenis penggunaan bahasa pada tulisan blog mahasiswa di Universitas Terbuka, sampel pada kajian ini adalah tulisan blog dari 5 mahasiswa pada jurusan yang berbeda-beda, topik dan materi tulisan beragam, mulai dari pendidikan, kesehariaan, gaya hidup hingga wirausaha. Kesimpulan kajian ini, mahasiswa dapat menggunakan blog sebagai forum untuk mendiskusikan ide dan pemikiran mereka, selain itu penggunaan bahasa yang digunakan berbeda agar maksud dan tujuan dari materi yang tulisan bisa dicerna dan dipahami dengan baik oleh beragam kalangan.
\end{abstract}

Kata kunci : blog, tulisan, informasi, komunikasi digital media

\begin{abstract}
Blogs or web blogs are one of the most popular web applications today that contain writing that can be accessed online. The writing presented on the blog is one part of digital media that is quite popular in discussing and sharing information quickly and accurately. This study describes the use of blog posts that are used in terms of information, comparison, content material and writing ideas that are uploaded in writing. The research method in this paper is a qualitative method, with an analysis or study of the text contained in the blog posts of the Open University students. This study tries to examine the types of language use in student blog posts at the Open University, the sample in this study is the blog posts of 5 students in different majors, the topics and writing materials vary, ranging from education, daily life, lifestyle to entrepreneurship. The conclusion of this study, students can use blogs as a forum to discuss their ideas and thoughts, in addition to using different languages so that the intent and purpose of the written material can be digested and understood well by various groups.
\end{abstract}

Keywords: blog, writing, information, digital media communication

\section{Pendahuluan}

Saat ini beragam jenis media yang bisa digunakan untuk berbagi informasi, mulai dari media sosial, media tercetak, media terpasang yang sangat massif dalam berbagi informasi. Media ini digunakan dengan beragam tujuan, bisa ditujukan untuk kegiatan politik, ekonomi, budaya, hiburan, entertainmen hingga pendidikan.

Beragam media yang beredar bisa digunakan baik secara gratis maupun berbayar. Banyaknya media yang ditawarkan bisa menjadikan banyak orang untuk dapat berkreasi dan beraktivitas menggunakan media. Saat ini juga masyarakat lebih berlomba-lomba untuk bisa menampilkan sesuatu yang terkini, tercepat dan lebih faktual. Media yang digunakan juga beragam, mulai dari pesan berantai dari whatsapp hingga website yang bisa diakses.

Saat ini salah satu web yang paling sering digunakan dan populer adalah web blog atau blog. Blog merupakan salah satu aplikasi web yang sangat popular saat ini berisi tulisan yang bisa di akses secara online. Penulis blog atau blogger akan selalu memberikan beragam informasi mulai dari hal yang kecil dan ringan hingga paparan diskusi yang berat serta banyak menimbulkan kontroversi jenis tulisan blog dapat disebut dengan postingan di blog dan para blogger juga memiliki beragam komunitas yang mempunyai tujuan serta tulisan yang beragam 
hingga menulis bersama untuk dapat menyajikan informasi secara menyeluruh.

Secara umum, tulisan yang tersaji di blog merupakan salah satu bagian dari media digital yang cukup digemari dalam membahas serta berbagi informasi secara cepat dan akurat, sehingga banyak sekali tulisan yang bisa dibaca oleh masyarakat, permasalahannya terkadang banyak sekali tulisan yang tersedia tidak melalui proses editing dan filter sehingga materi tulisan ada yang memiliki beragam referensi yang dapat digunakan dan tidak.

Mahasiswa Universitas Terbuka juga memiliki beragam tulisan di blog, banyak sekali jenis tulisan blog yang dilakukan oleh mahasiswa, mulai dari seputar kegiatan seharihari hingga mengenai sistem pendidikan hingga ulasan mengenai Universitas Terbuka.

\section{Kajian Literatur \\ Sumber Belajar Pada Teknologi dan Komunikasi}

Sebagai salah satu cara belajar yang harus terintegrasi dengan teknologi dan informasi juga berpengaruh pada kinerja dan cara guru dan siswa dalam berinteraksi pada proses belajar dan mengajar. Sumber belajar yang digunakan juga beragam, mulai dari perpustakaan hingga perpustakaan online.

Salah satu instansi pendidikan dalam sebuah asosiasi memaparkan bahwa teknologi dan komunikasi yaitu AECT (Association of Education Communication Technology) melalui pengertian dari The Definition of Educational Technology menjelaskan sumber belajar yang digunakan pada dasarnya terdiri dari 6 jenis, yaitu :

1. Pesan

Pesan merupakan salah satu bagian komunikasi yang paling sederhana dan simpel, pesan merupakan sumber informasi atau inti hal yang ingin disampaikan atau diteruskan. Secara umum pesan dapat dibagi pada beberapa jenis, seperti ide, fakta, data, gagasan dan analisis. Hal ini bisa berlaku untuk beragam bidang seperti mata kuliah, pengajaran yang diajarkan dan juga bias disebarluaskan kepada mahasiswa atau khalayak umum.

2. Manusia

Manusia merupakan salah satu sumber belajar yang umum karena pengetahuan yang dimiliki bisa disseminasikan dan juga disebarluaskan melalui perkataan dan ucapan dari beragam sumber serta rujukan yang bisa dibuktikan secara nyata. Pada umumnya sumber media manusia seperti dosen, tutor, guru, pendidik, penyaji, narasumber hingga orang yang profesional dan berpengalaman di bidangnya.

3. Bahan dan materi

Bahan yang bias digunakan sebagai sumber untuk bias dilakukan dalam proses belajar dan mengajar, selain itu perangkat bahan dan materi juga bias diselaraskan dengan teknologi serta membantu dalam mendistribusikan materi,hal ini bias seperti buku, kertas, sebaran kuliah, poster, koran, majalah dan lainnya.

4. Perangkat dan alat

Fasilitas yang mendukung menjadi salah satu bagian yang sangat penting dalam proses pembelajaran. Alat yang dapat digunakan untuk menyampaikan pesan dalam bahan, seperti infokus, slide, power point, dan lainnya.

5. Teknik

Panduan dan prosedur yang digunakan dalam penggunaan bahan, peralatan dan lainnya dalam menyampaikan pesan yang diinginkan,hal ini seperti diskusi, tanyajawab, simulasi dan sebagainya. Beragam teknik yang bisa digunakan dapat berpengaruh pada kegiatan dan interaski oleh siswa.

6. Lingkungan

Lingkungan juga merupakan salah satu bagian yang bias mempengaruhi sumber belajar yang bias kita perlukan, melalui lingkungan yang baik dan kondusif bisa memungkinkan kita mendapatkan materi dan bahan belajar dengan baik, lingkungan yang baik seperti kelas, perpustakaan, kantor dan lainnya, saat ini juga sekolah alam yang langsung berinteraksi pada lingkungan berpengaruh pada siswa untuk bisa belajar langsung dengan lingkungan yang ada di sekitarnya.

\section{Implementasi Teknologi, Informasi, dan Komunikasi (TIK)}

Perkembangan teknologi ini merubah banyak cara agar dapat menyebarkan informasi, pesatnya pertumbuhan teknologi ini berpengaruh dengan perilaku manusianya, tidak bisa dipungkiri bahwa perangkat aplikasi 


\section{Jurnal Ilmu Komunikasi, Vol.8 No.2 September 2021}

online sudah merajai dan bisa melampaui perangkat konvensional.

Banyak cara yang bisa dilakukan untuk membantu meningkatkan literasi informasi, di Indonesia, melalui kegiatan seminar, pelatihan, bimbingan dan kehadiran perpustakaan online menstimulus banyak individu untuk aktif dalam menulis. Sesuai dengan kebijakan kementerian pendidikan dan Undang-undang dasar bahwa pendidikan adalah hak semua individu, maka dengan adanya penerapan teknologi, informasi dan komunikasi membantu penyebaran secara menyeluruh dari sabang sampai merauke.

Sosial media dan sosial network merupakan salah satu perangkat untuk penyebaran informasi melalui teknologi, informasi dan komunikasi. Melalui media tersebut, informasi yang disebar bisa didapatkan dengan cepat, mudah, murah dan terkini.

Pendidikan merupakan salah satu bagian yang bisa merasakan dampak penggunaan teknologi, informasi dan komunikasi. Melalui beragam media, pendidikan dapat dirasakan oleh semua elemen masyarakat yang tidak tersentuh. Universitas Terbuka contohnya, selain menerapkan beragam perangkat online maupun offline, media yang digunakan bisa terakses oleh seluruh masyarakat di Indonesia bahkan di dunia.

\section{Blog Sebagai Media Berbagi Informasi}

Maraknya serta populernya blog di kalangan masyarakat tidak terlepas dari banyaknya akses, ketersediaan dan juga sarana dan prasarana yang bisa dilakukan oleh penggunanya, blog juga dapat menjadi salah satu sumber referensi yang cukup baik karena ditulis berdasarkan data dan fakta di lapangan maupun hal yang sudah terjadi dan dialami oleh penulisnya, meskipun harus tetap melakukan pengecekan terhadap sumber dan referensi yang di rujuk oleh pengguna tersebut.

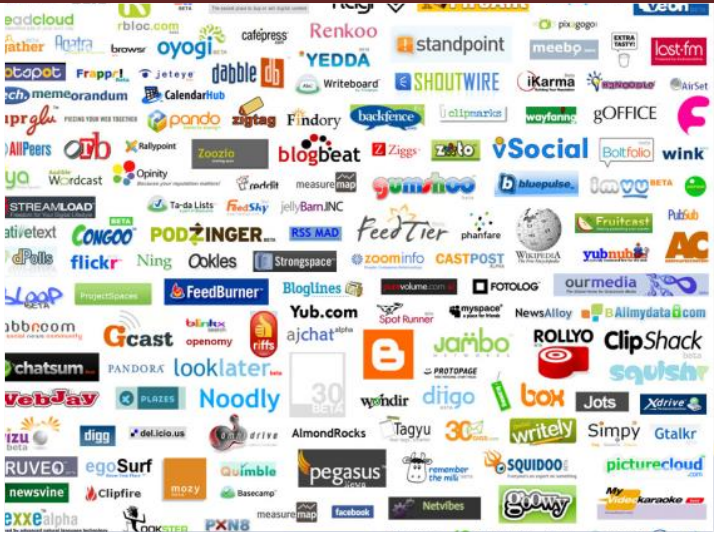

Gambar 1. Beragam jenis blog yang bisa digunakan

Pada 5 sampai 10 tahun yang lalu, pengguna blog masih bisa di hitung dengan jari, harl ini karena terbatasnya fasilitas dan sarana infrastruktur untuk akses internet dan literasi informasi yang dimiliki oleh masyarakat. Pada beberapa tahun belakangan ini, sudah ada banyak sekali web yang menyediakan jasa untuk dapat membuat akun penulisan blog, ada yang gratis dan berbayar, kelebihannya terdapat pada fitur, pembuatan nama serta data yang dimiliki oleh pengguna blog tersebut.

\section{Internet Users in the World} by Regions - June 30, 2017
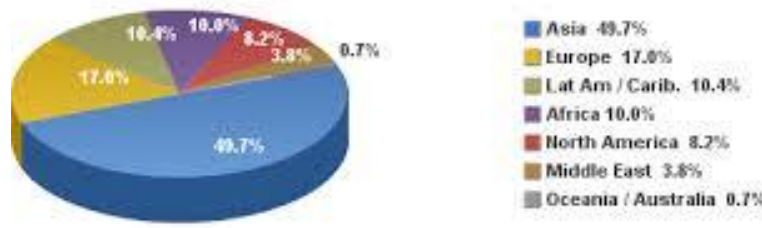

Source Internet World Stats - unww intemetworldstats comistats $\mathrm{Atr}$ Basis: 3, 885, 567, 619 Internet users in Jure 30, 2017

Copvright Q 2017, Winiwatts Marketing Group

Gambar 2. Pengguna Internet di Seluruh Dunia

Berdasarkan data di atas, ada beberapa hal yang menarik yang bisa dilihat, data tersebut di ambil pada bulan Juni 2017, sumber dari Miniwatts marketing grup bahwa pengguna internet di dunia pertama di pegang oleh Asia, Eropa dan Amerika menjadi setelahnya. Artinya pengguna internet yang cukup tinggi juga mengakibatkan beragam informasi yang tersedia di dalam internet tersebut. 


\section{Jurnal Ilmu Komunikasi, Vol.8 No.2 September 2021}

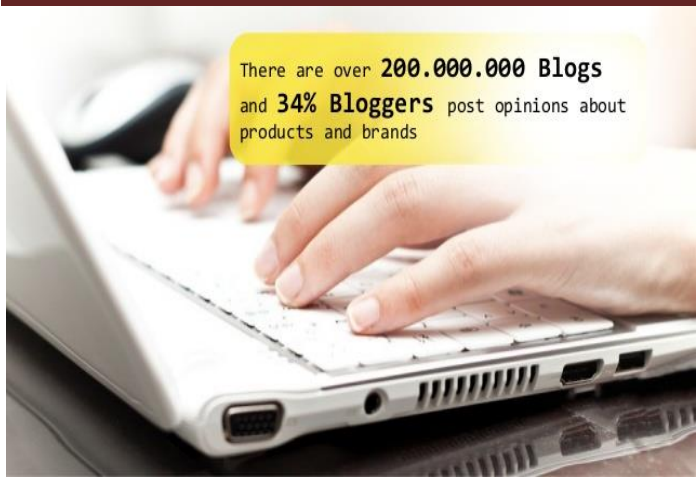

Gambar 3. Data Pengguna Blog di Indonesia

Pada tahun 2017, kantor berita Antara mengeluarkan data bahwa saat ini lebih dari 200 juta pengguna blog, sekitar 34\% blog di antaranya mengenai jenis produk dan brand tertentu. Banyaknya pengguna blog di Indonesia juga menjadi referensi tulisan yang dapat dijadikan sumber bacaan bagi masyarakat secara luas.

Pada data tersebut, jenis blog juga selain untuk umum, bisnis dan produk, blog bisa diterapkan pada dunia pendidikan. Secara umum Rouf dan Sopyan (2007) mendeskripsikan bahwa terdapat tiga jenis blog pada pendidikan, yaitu:

\section{- Blog Tutor}

Informasi blog tutor lebih terarah dan berisi tentang akademik, umumnya blog ini ditulis oleh dosen, tutor, akademisi, professional dan orang yang berkecimpung di dunia pendidikan. Umumnya isi blog tutor lebih mengulas mengenai kurikulum, silabus, informasi secara rinci dan detail tentang mata kuliah tertentu, kegiatan penilaian dan laiinya. Selain itu, biasanya dosen juga menuliskan beberapa cara, trik, tips serta pengalaman hidup yang bisa dibaca oleh masyarakat umum. Para dosen juga banyak memberikan ide penelitian, kolaborasi dan diskusi yang bisa direspon oleh mahasiswa maupun dosen lain. Pada blog ini, bahasa yang digunakan lebih formal dan dilengkapi dengan data dan fakta yang ada di lapangan. Beberapa bagian yang bisa dilakukan untuk blog bagi tutor adalah :

$\checkmark$ Web based courses

$\checkmark$ Kuliah Maya (Virtual courses)

$\checkmark$ Blog untuk kuliah maya, memuat:

- Daftar mata kuliah

- Silabus

- Materi kuliah (ppt, pdf, doc, jpg, dll)

- Referensi (e-book, url addres)
- Pengumuman2, tugas2

- Forum diskusi (milis, chating, instant messenger)

- Profil dan kontak dosen

- Materi ujian atau kisi-kisi

- Blog Kelas.

Secara umum, blog kelas berisi kumpulan tulisan baik oleh mahasiswa maupun dengan dosen dengan materi tertentu, blog ini merupakan wadah kolaborasi yang baik untuk berdisuksi baik dalam sisi akademik maupun non akademik. Pada blog kelas, biasanya isi tulisan yang dirangkum mengenai kegiatan perkuliahan, tugas dan seputar permasalahan yang dihadapi pada mata kuliah tertentu. Blog kelas biasanya di inisasi oleh mahasiswa, terlebih mahasiswa pada kelas tertentu menulis, memberikan ide, tanggapan, evaluasi dan interaksi yang lebih mendalam terhadap mahasiswa lain di blog ini.

- Blog Mahasiswa.

Blog mahasiswa merupakan blog secara umum yang mudah dijumpai, pada intinya mahasiswa sering menulis kesehariannya di blog mengenai catatan yang dia lakukan sehari-hari. Pada blog ini, mahasiswa memberikan ide, pemikiran, catatan dan penggalaman mereka selama kuliah maupun di dunia secara nyata sehari-hari. Sifat tulisan blog mahasiswa lebih non formal agar dapat dibaca secara umum oleh mahasiswa yang lain. Blog mahasiswa bisa dikatakan sebagai blog yang bebas karena mahasiswa menulis sesuai perspektif mereka dan juga hanya untuk kepentingan pribadi.

Selain paparan di atas, blog juga memiliki beragam keuntungan yang bisa digunakan oleh masyarakat secara luas. Keuntungan Blog secara umum adalah :

- Mudah dibuat

- Cocok untuk semua user 
- Bisa dimanfaatkan sesuai kebutuhan pada tiap profesi

- Send of purpose; blog dibuat sesuai tujuan dan kebutuhan

- Melatih berpikir, menyampaikan pendapat, pengalaman, dan menulis.

- Sarana edukasi dan pemberdayaan

- Saling berbagi ekspresi dan informasi secara tertulis.

- Membentuk komunitas blogger

- Berdiskusi mengenai blog dan permasalahannya

- Media komunikasi baru di internet yang populer.

- Masih banyak yang Gratis

\section{Metode Penelitian}

Metode penelitian pada tulisan ini adalah metode kualitatif, dengan analisis atau kajian teks yang terdapat pada tulisan blog pada mahasiswa Universita Terbuka. Kajian ini mencoba menelaah jenis penggunaan bahasa pada tulisan blog mahasiswa di Universitas Terbuka, sampel pada kajian ini adalah tulisan blog dari 5 mahasiswa pada jurusan yang berbeda-beda, topik dan materi tulisan beragam, mulai dari pendidikan, kesehariaan, gaya hidup hingga wirausaha.

Pendekatan yang digunakan dalam mengumpulkan data kualitatif menerapkan 3 bagian. Pertama, blog dari 5 mahasiswa UT dianalisis selama satu semester bersama dengan persepsi mahasiswa dan pengamatan peneliti. Kedua, survei dibagikan kepada mahasiswa di akhir semester, dan terakhir, dilakukan diskusi mengenai penggunaan media sosial, keterampilan dan kebutuhan mereka serta masalah yang dihadapi.

\section{Pembahasan}

Beragam keuntungan blog semakin membuat situs ini populer dan ada banyak peluang sebagai salah satu mata pencaharian, seperti ada blogger dari mahasiswa Universitas Terbuka yang menjadikan blognya sebagai salah satu bagian untuk mengikuti kompetisi dan perlombaan yang dimenangkan hingga mendapatkan beragam hadiah menarik, pada mahasiswa tersebut lebih dari 100 kegiatan perlombaan menulis di blog di menangkan dengan berbagai macam hadiah yang beragam.

Pada umumnya, blog dapat digunakan sebagai media berbagi informasi, saat ini jumlah komunitas pada blog tertentu semakin hari semakin banyak, selain itu ada beberapa pelatihan yang diberikan kepada komunitas tersebut agar dapat lebih memanfaatkan tulisan-tulisan tersebut menjadi lebih baik.

Ada juga beberap blogger yang sudah tidak aktif, hal ini karena kesibukan penulis serta materi yang sudah tidak dituliskan penulisnya, meskipun sudah tidak aktif namun tulisan yang tersedia masih bisa dibaca dan dinikmati oleh orang yang dapat mengakses situs tersebut.

Pada dunia Pendidikan, blog juga memiliki penanan yang cukup penting, banyak dosen, guru, tutor serta pengajar yang memanfaatkan secara maksimal dengan memberikan materi bahan ajarnya melalui blog, hal ini berdampak sangat luas karena dapat dipelajari oleh siswa lain di seluruh Indonesia bahkan ada di dunia. Pengguna blog di seluruh dunia juga sering berkumpul secara dunia maya dengan adanya beragam forum dan sosial media yang dapat membahas beragam tulisan serta masukan untuk lebih nyata.

\section{Beberapa Hasil Tulisan Blog Mahasiswa Universitas Terbuka}
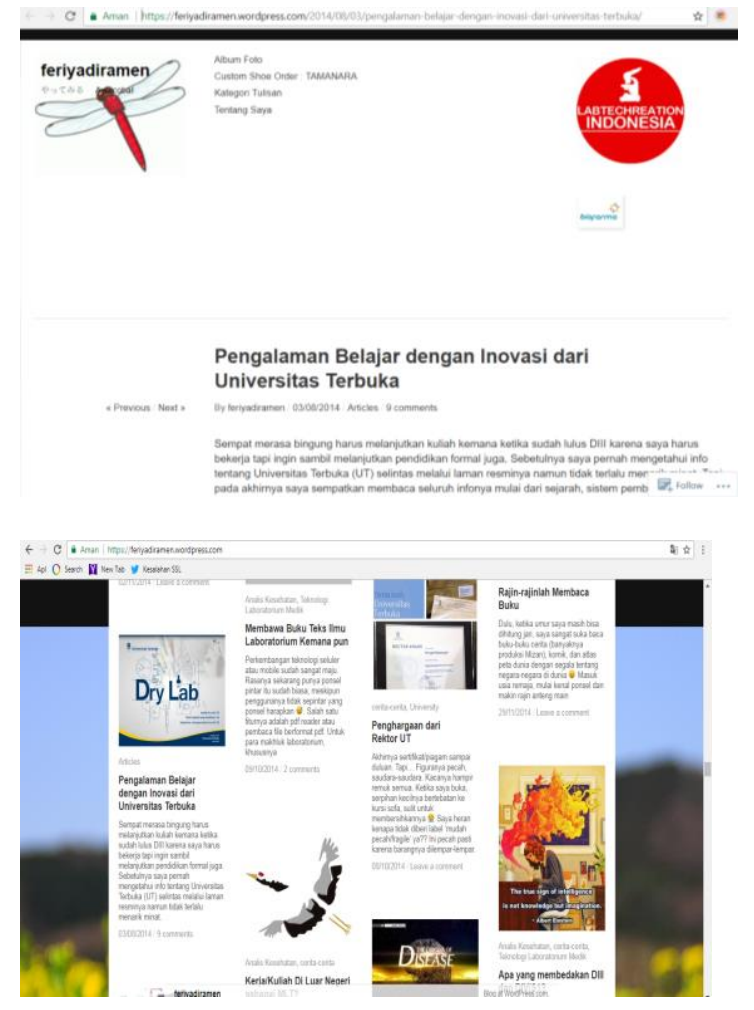


\section{Jurnal Ilmu Komunikasi, Vol.8 No.2 September 2021}

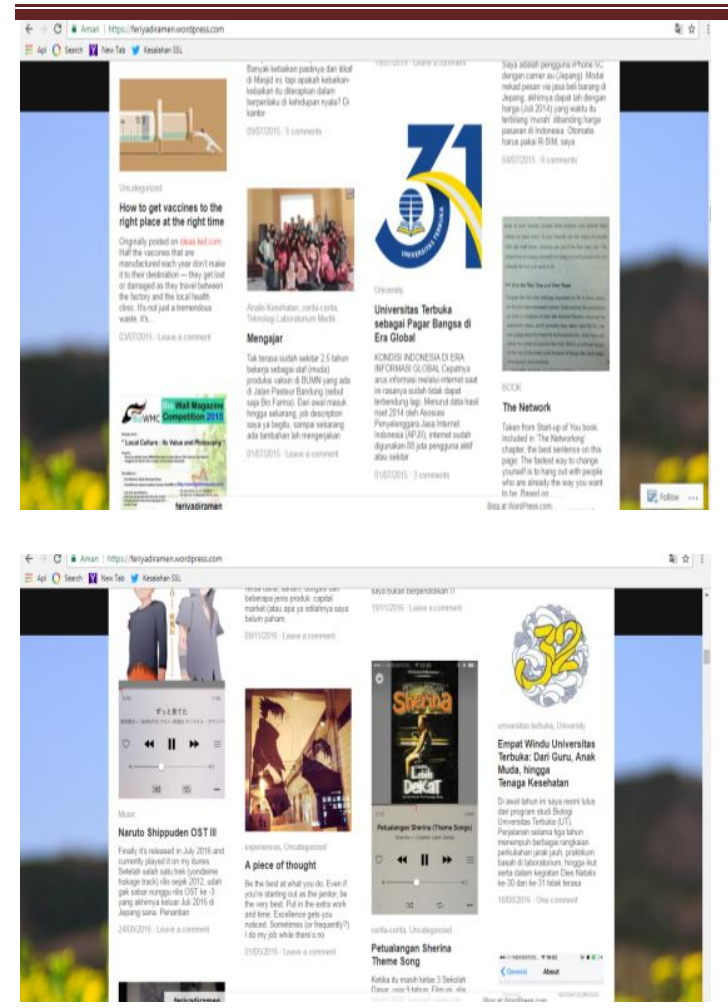

Blog mahasiswaa.n. Feriyadi Ramansyah,, Sumber :

http://feriyadiramen.wordpress.com/2014/08/0 3/pengalaman-belajar-dengan-inovasi-dariuniversitas-terbuka/

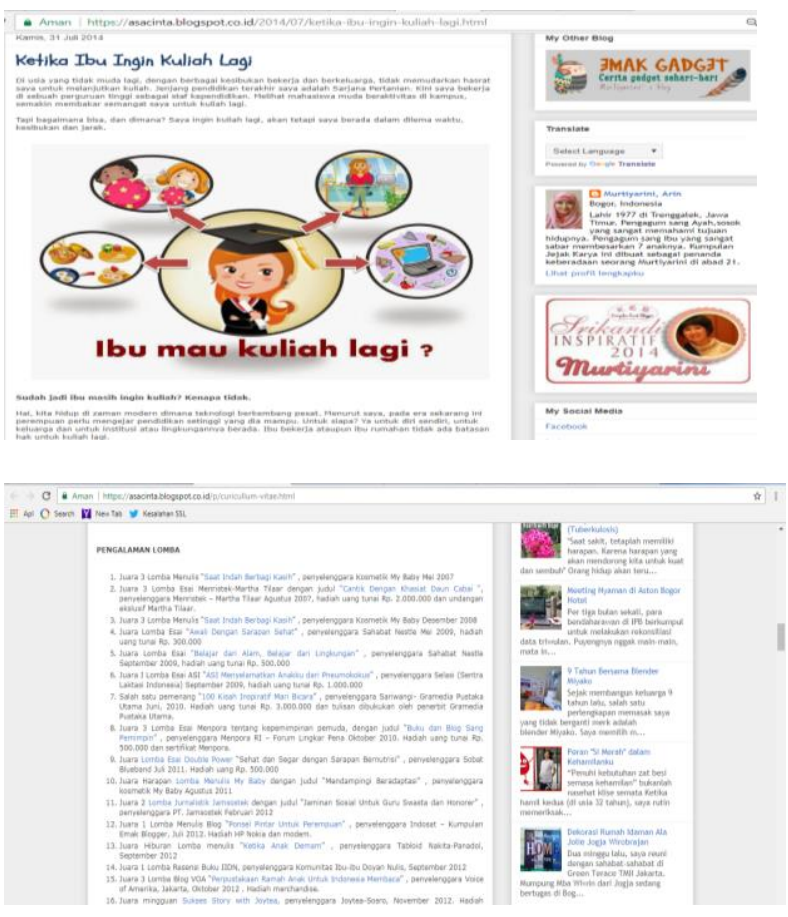

Blog mahasiswa Siti Nurjanah

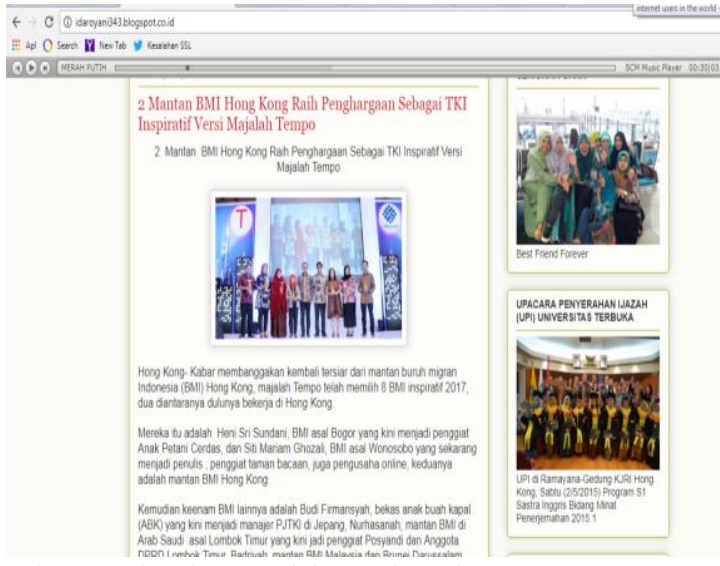

Sumber :

http://nsiti7.blogspot.co.id/2015/06/melangkah -pasti-bersama-universitas.html

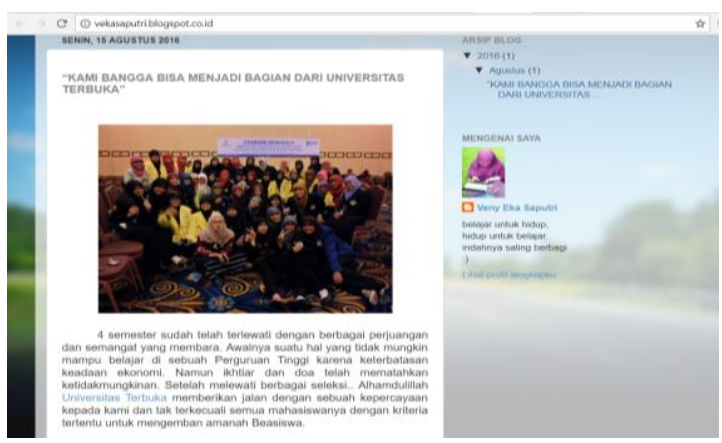

Blog mahasiswa Venny Eka Saputri Sumber :

http://vekasaputri.blogspot.co.id/2016/08/kami -bangga-bisa-menjadi-bagian-dari.html

Blog mahasiswa Murtiyarni

Sumber:

https://asacinta.blogspot.co.id/2014/07/ketikaibu-ingin-kuliah-lagi.html 


\section{Jurnal Ilmu Komunikasi, Vol.8 No.2 September 2021}

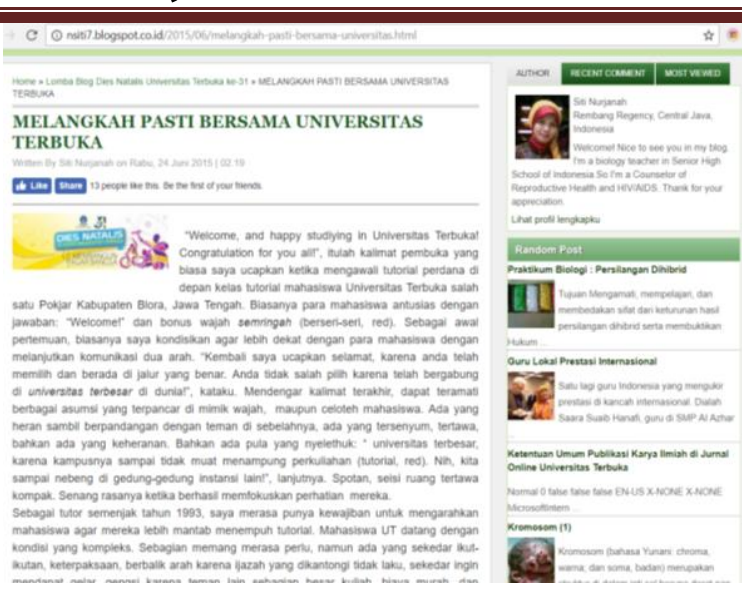

\section{Kesimpulan}

Secara umum, mahasiswa dapat menggunakan blog sebagai forum untuk mendiskusikan ide dan pemikiran mereka, mahasiswa Universitas Terbuka banyak sekali menggunakan media blog untuk bisa memaparkan ide dan pemikiran mereka terhadap apa yang mereka hadapi dan rasakah. Secara lebih rinci, mahasiswa menggunakan bahasa yang digunakan agak berbeda, sehingga maksud dan tujuan dari materi yang tulisan bisa dicerna dan dipahami dengan baik oleh beragam kalangan. Pada intinya, blog merupakan salah satu sarana yang cukup baik untuk bisa memberikan informasi yang menarik dengan cepat, tepat dan bisa dijadikan referensi dalam akademik. Hal ini dilakukan oleh banyak akademisi dan mahasiswa Univesitas Terbuka untuk dapat mengulas mengenai, layanan, fasilitas, kuriukulum, tutor hingga evaluasi yang mereka dapatkan.

\section{REFERENSI}

Assael, H., 2001, $6^{\text {th }}$ ed, Consumer Behavior and Marketing Action, New York University: South Western College Publishing.

Ariasari, Fany. 2006. Pernah pernik Blog

Cantik, Aktraktif dan Fungsional. Jakarta : Mediakita

Enterprise, Jubilee. 2008. Teknik menjadi penulis Blog bayaran. Jakarta : Elex Media Komputindo.

Jonassen, David. 2004 AECT. Handbook of Research on Educational Communications and

Rouf dan Sopyan. 2007. Panduan Praktis

Mengelola Blog untuk Pemula. Jakarta :

Mediakata Redaksi.

Technology. New Jersey : Lawrence Erlabrum.

https://www.antaranews.com/ https://www.internetworldstats.com http://feriyadiramen.wordpress.com https://asacinta.blogspot.co.id http://idaroyani343.blogspot.co.id http://nsiti7.blogspot.co.id http://vekasaputri.blogspot.co.id

Biodata Penulis

Yasir Riady merupakan pengajar di Universitas Terbuka. 